Article

\title{
Sex-Related Differences in the Maximal Lactate Steady State
}

\author{
Paul S. Hafen and Pat R. Vehrs * (D) \\ Department of Exercise Sciences, 106 SFH; Brigham Young University; Provo, UT 84602, USA; \\ basicrunner2002@yahoo.com \\ * Correspondence: pat_vehrs@byu.edu
}

Received: 27 October 2018; Accepted: 21 November 2018; Published: 27 November 2018

\begin{abstract}
The maximal lactate steady state (MLSS) is one of the factors that differentiates performance in aerobic events. The purpose of this study was to investigate the sex differences in oxygen consumption $\left(\mathrm{VO}_{2}\right)$, heart rate (HR), and the respiratory exchange ratio (RER) at the MLSS in well-trained distance runners. Twenty-two (12 female, 10 male) well-trained distance runners ( $23 \pm 5.0$ years) performed multiple 30-min steady-state runs to determine their MLSS, during which blood lactate and respiratory gas exchange measures were taken. To interpret the MLSS intensity as a training tool, runners completed a time-to-exhaustion (TTE) run at their MLSS. The relative intensity at which the MLSS occurred was identical between males and females according to both oxygen consumption $\left(83 \pm 5 \% \mathrm{O}_{2} \max\right.$ ) and heart rate $(89 \pm 7 \% \mathrm{HRmax})$. However, female runners displayed a significantly lower RER at MLSS compared to male runners $(p<0.0001$; $0.84 \pm 0.02$ vs. $0.88 \pm 0.04$, respectively). There was not a significant difference in TTE at MLSS between males $(79 \pm 17 \mathrm{~min}$ ) and females $(80 \pm 25 \mathrm{~min})$. Due to the observed difference in the RER at the MLSS, it is suggested that RER derived estimates of MLSS be sex-specific. While the RER data suggest that the MLSS represents different metabolic intensities for males and females, the relative training load of MLSS appears to be similar in males and female runners.
\end{abstract}

Keywords: competitive; running; runners; female; respiratory exchange ratio (RER); maximal lactate steady-state (MLSS)

\section{Introduction}

Performance in aerobic events is largely dependent on maximal sustainable power or velocity. The oxygen consumption $\left(\mathrm{VO}_{2}\right)$ at this velocity is referred to as the performance $\mathrm{VO}_{2}$ [1], and is primarily determined by the maximal lactate steady state (MLSS) or lactate threshold [2]. The velocity at the performance $\mathrm{VO}_{2}$ is the best physiological predictor of distance running performance [2]. Unfortunately, the determination of the MLSS is laborious, as the associated blood lactate analysis requires the collection of multiple blood samples multiple 30-min exercise tests. Thus, the development of less demanding methods to estimate the MLSS would be beneficial.

The respiratory exchange ratio (RER) is typically used to estimate caloric expenditure and oxidative substrate utilization [3]. The RER can also be used to identify differences in training status and muscular efficiency $[4,5]$. Key factors that influence the RER during exercise include intensity of exercise, muscle fiber composition, and the timing and composition of pre-exercise food consumption [6]. Previous reports [7,8] indicate that during submaximal-intensity aerobic exercise, females demonstrate lower RER values and higher fat utilization rates than their male counterparts.

Previous studies have observed RER values near 1.0 at intensities corresponding to the MLSS $[9,10]$. Thus, it has been suggested that an intensity of exercise corresponding to an RER $=1.0$ may represent a practical, non-invasive approximation of the intensity of exercise corresponding to 
the MLSS [11,12]. Despite evidence that submaximal steady-state RER is influenced in part by training volume [6] and sex [7], most of the research investigating the relationship between the RER and the MLSS has been done exclusively in either untrained [13], recreationally active [11,14,15], and/or well-trained $[9,12,16-18]$ males. One study [19] that investigated sex-related differences in the relationship between the RER and the MLSS used a heterogeneous group that participated in a variety of endurance, strength training, and other physical activities, without specific reports on the training status or aerobic capacity $\left(\mathrm{VO}_{2} \max \right)$ of the participants. Therefore, the purpose of this study was to investigate whether common physiological variables $\left(\mathrm{VO}_{2}\right.$, heart rate (HR), RER) at the MLSS might be influenced by sex in a more homogeneous group of well-trained distance runners. We hypothesized that females would exhibit a lower RER at the MLSS, and that this lower RER would improve MLSS performance by prolonging the time-to-exhaustion (TTE) while running at the velocity associated with the MLSS (vMLSS).

\section{Methods}

\subsection{Subjects}

Twelve female $(21.1 \pm 3.9$ years, $167.9 \pm 7.0 \mathrm{~cm}, 58.5 \pm 5.2 \mathrm{~kg})$ and 10 male $(27.2 \pm 3.8$ years, $179.6 \pm 8.1 \mathrm{~cm}, 72.6 \pm 5.2 \mathrm{~kg}$ ) runners voluntarily participated in this study. To establish training status, all participants had [1] a $5000 \mathrm{~m}$ personal best time that was within $30 \%$ of the current world record time (i.e., $18.00 \mathrm{~min}$ for males and $20.25 \mathrm{~min}$ for females), and [2] been running at least 4-8 miles per training session for 3 or more days/week over the preceding 6 months. All participants provided written, informed consent after all procedures and potential risks and benefits were explained. This study was approved by the Institutional Review Board for the use of human subjects.

Female runners were tested within the first 14 days of their menstrual cycle, defined as the follicular phase of menses. This was done to minimize the potential confounding effects of intra-individual hormone variability through the menstrual cycle, characterized by elevated estradiol levels during the later phases of menses. Such increases in estradiol have been directly linked to reduced blood lactate concentrations and increased fat oxidation rates during submaximal exercise [20-22].

\subsection{Experimental Design}

This study consisted of 3-6 exercise-testing sessions over the course of 10-14 days. During the first session, participants completed a maximal treadmill graded exercise test (GXT) to determine their $\mathrm{VO}_{2}$ max. During subsequent exercise testing sessions, participants completed 30-min exercise tests at constant treadmill speeds to determine their individual MLSS. All runners completed each of the running trials following an overnight fast. Once the MLSS was identified, a time to exhaustion (TTE) test was completed at the vMLSS.

\subsection{Methodology}

\subsubsection{Maximal Exercise Testing}

All participants completed a treadmill (Trackmaster TMX425L, Full Vision Inc., Newton, KS, USA) GXT beginning at a speed of $9.7 \mathrm{~km} \cdot \mathrm{hr}^{-1}(6 \mathrm{mph})$ with a $1.5 \%$ grade. The grade remained constant throughout the test and the treadmill speed was increased by $1 \mathrm{~km} \cdot \mathrm{hr}^{-1}(0.6 \mathrm{mph})$ every $3 \mathrm{~min}$ until subjects fatigued and voluntarily terminated the exercise test despite verbal encouragement. Respiratory gas exchange variables were measured continuously (TrueOne 2400, ParvoMedics, Sandy, UT, USA). Heart rate (HR) was measured using a chest-strap HR monitor (Polar Electro OY, Hong Kong). Ratings of perceived exertion (RPE) were monitored at the end of each 3 min stage using the Borg 15-point scale [23]. 
Each runner's effort during the GXT was considered maximal if there was a plateau in oxygen consumption $\left(\mathrm{VO}_{2}\right)$ despite an increase in workload at the final stage. A plateau in $\mathrm{VO}_{2}$ was defined as an increase in $\mathrm{VO}_{2}$ of less than one-half of the increase expected from the increase in speed. In the absence of a plateau, two of the following criteria were considered requisite for the determination of aerobic capacity: (1) a maximal RER $\geq 1.10$, (2) a maximal HR greater than $90 \%$ of age-predicted maximal HR $(208-(0.7 \times$ age $))$, and/or (3) a final RPE $\geq 18$.

\subsubsection{MLSS Testing}

During the MLSS running trials, respiratory gas exchange variables and HR were continuously monitored as described for the GXT. The MLSS was defined as the highest steady-state blood lactate concentration (cMLSS) and corresponding vMLSS that could be achieved during a 30 min running trial at a constant speed. Blood lactate concentrations were considered steady-state if blood lactate increased by less than $1 \mathrm{mmol}$ between the 10th and 30th min of the $30 \mathrm{~min}$ running trial. The cMLSS and vMLSS were identified from multiple $30 \mathrm{~min}$ submaximal running trials completed on separate days. The running trials began three to four days following the maximal GXT and each submaximal running trial was separated by $48 \mathrm{~h}$. For each MLSS trial, an indwelling venous catheter was inserted into an antecubital vein in order to obtain small $(\approx 2 \mathrm{~mL})$ blood samples at 5 min intervals without interrupting the 30 min running trials.

Plasma lactate concentrations for each of the running trials were obtained using a calibrated clinical grade lactate analyzer (YSI 2300 STAT Plus ${ }^{\mathrm{TM}}$, YSI Life Sciences, Yellow Springs, OH, USA). Briefly, approximately $135 \mu \mathrm{L}$ of blood was separated from each sample for centrifugation in order to obtain triplicate measures of hematocrit. An additional $60 \mu \mathrm{L}$ was separated from each blood sample for triplicate measures of hemoglobin content according to the standard clinical technique using a cyanomethemoglobin reagent via a photometric multilable counter (VICTOR ${ }^{3} 1420$ Multilabel Counter, PerkinElmer, Waltham, MA, USA). The remainder of each sample was centrifuged for plasma lactate analysis in the YSI 2300 STAT Plus ${ }^{\mathrm{TM}}$. Each plasma lactate sample was adjusted to account for any shifts in blood volume that might occur due to the duration of each running trial [24].

The initial MLSS running speed was determined following the GXT, beginning at a velocity associated with $80 \%$ of the participant's $\mathrm{VO}_{2}$ max. Following the initial running trial, running speed was adjusted appropriately for subsequent trials. If, during the preceding running trial, plasma lactate concentration increased by more than $1 \mathrm{mmol}$ between the 10th and 30th min, the running speed during the subsequent trial was decreased by $0.6 \mathrm{~km} \cdot \mathrm{hr}^{-1}(0.4 \mathrm{mph})$. Conversely, if the lactate concentration increased by less than $1 \mathrm{mmol}$ between the 10th and 30th minute, the speed of the subsequent trial was increased by $0.6 \mathrm{~km} \cdot \mathrm{hr}^{-1}(0.4 \mathrm{mph})$. This protocol allowed for the determination of cMLSS and vMLSS in as few as two, but no more than four, $30 \mathrm{~min}$ running trials for all runners.

To test the notion that an intensity of exercise eliciting an RER $=1.0$ corresponded to the MLSS, and to determine the duration that this intensity could be maintained, a subset of 8 runners began MLSS testing at an intensity of exercise that elicited an RER as close as possible to 1.0. The speed of the treadmill was adjusted during the first several minutes of the exercise test to allow the participant to achieve an RER near 1.0. The exercise test progressed without any further changes in treadmill speed and the participant was then encouraged to run as long as possible.

\subsubsection{TTE Testing}

Approximately $48 \mathrm{~h}$ following the final MLSS running trial, each runner completed a TTE running trial at their personal vMLSS. Fluid ingestion was not permitted during the TTE running trial. Each participant received verbal encouragement from the researchers and were instructed to run at the assigned speed for as long as they were able. The TTE trial ended when participants felt unable to continue running at their vMLSS. 


\subsection{Statistical Analysis}

A two-way mixed analysis of variance (ANOVA) was used to compare the physiological data from the MLSS trials in order to properly account for variability between groups (male vs. female) over time (5 min intervals). The mixed ANOVA was the appropriate test for our analyses as each subject had multiple observations. Group means were compared using independent t-tests. All analyses were completed using SAS JMP ${ }^{\circledR}$ Pro 12.0.1 statistical software. The alpha level for statistical analysis was set at 0.05 .

\section{Results}

Table 1 includes the self-reported training volume, $5000 \mathrm{~m}$ personal best times, and the results from the GXT. Five (50\%) males and $8(67 \%)$ females demonstrated a $\mathrm{VO}_{2}$ plateau on the GXT. All other runners met other criteria for maximal effort. Compared to females, the $\mathrm{VO}_{2}$ max in males was $35 \%$ higher $(p<0.05)$ when expressed in absolute $\left(\mathrm{L} \cdot \mathrm{min}^{-1}\right)$ terms and $7 \%$ higher when expressed relative to $\left(\mathrm{mL} \cdot \mathrm{kg}^{-1} \cdot \mathrm{min}^{-1}\right)$ body mass. There were no differences $(p>0.05)$ in maximal HR or RER between the male and female runners.

Table 1. Maximal Exercise Test Results.

\begin{tabular}{ccc}
\hline & Males $(\mathbf{n}=\mathbf{1 0})$ & Females $(\mathbf{n}=\mathbf{1 2})$ \\
\hline $5000 \mathrm{~m}$ Best Time $(\mathrm{min})$ & $16.8 \pm 0.8$ & $17.7 \pm 1.1^{*}$ \\
\hline Training Volume $\left(\mathrm{km} \cdot \mathrm{wk}^{-1}\right)$ & $67.9 \pm 23.0$ & $85.8 \pm 28.0$ \\
\hline $\mathrm{VO}_{2} \max \left(\mathrm{L} \cdot \mathrm{min}^{-1}\right)$ & $4.5 \pm 0.3$ & $3.4 \pm 0.2^{*}$ \\
\hline $\mathrm{VO}_{2} \mathrm{max}\left(\mathrm{mL} \cdot \mathrm{kg}^{-1} \cdot \mathrm{min}^{-1}\right)$ & $62.9 \pm 4.5$ & $59.0 \pm 3.2^{*}$ \\
\hline $\mathrm{HRmax}(\mathrm{bpm})$ & $186.4 \pm 10.5$ & $193.8 \pm 9.9$ \\
\hline RERmax & $1.01 \pm 0.03$ & $1.00 \pm 0.03$ \\
\hline
\end{tabular}

Values reported are means \pm SD. ${ }^{*}$ Significant difference $(p<0.05)$ between males and females.

Table 2 summarizes the results of the MLSS running trial. The cMLSS was significantly lower $(p=0.0402)$ in the female runners $\left(1.79 \pm 0.49 \mathrm{mmol} \cdot \mathrm{L}^{-1}\right)$ compared to the male runners $\left(2.59 \pm 1.14 \mathrm{mmol} \cdot \mathrm{L}^{-1}\right.$; Table 2, Figure 1). The RER at the MLSS in female runners $(0.84 \pm 0.02)$ was also significantly lower $(p<0.0001)$ than the RER observed in the male runners $(0.88 \pm 0.04)$ (Table 2, Figure 1). At the MLSS, RER was significantly lower than $1.0(p<0.0001)$ for both male and female runners. Additionally, there was not a significant effect of time on RER $(p=0.6631)$ during the MLSS trial.

Table 2. Maximal Lactate Test Results.

\begin{tabular}{ccc}
\hline & Males $(\mathbf{n}=\mathbf{1 0})$ & Females $(\mathbf{n}=\mathbf{1 2})$ \\
\hline $\mathrm{VO}_{2}\left(\mathrm{~mL} \cdot \mathrm{kg}^{-1} \cdot \mathrm{min}^{-1}\right)$ & $52.4 \pm 3.8$ & $49.1 \pm 2.9$ \\
\hline $\mathrm{VO}_{2}\left(\% \mathrm{VO}_{2} \mathrm{max}\right)$ & $83.3 \pm 4.6$ & $83.0 \pm 6.7$ \\
\hline $\mathrm{cMLSS}\left(\mathrm{mmol} \cdot \mathrm{L}^{-1}\right)$ & $2.59 \pm 1.14$ & $1.79 \pm 0.49 *$ \\
\hline $\mathrm{HR}(\mathrm{bpm})$ & $166.3 \pm 11.2$ & $171.3 \pm 9.4$ \\
\hline $\mathrm{HR}(\% \mathrm{HRmax})$ & $89.5 \pm 8.8$ & $88.6 \pm 6.8$ \\
\hline RER & $0.88 \pm 0.04$ & $0.84 \pm 0.02 *$ \\
\hline TTE $(\mathrm{min})$ & $79.0 \pm 17.0$ & $80.0 \pm 25.1$ \\
\hline
\end{tabular}

Values reported are means \pm SD at the maximal lactate. $\mathrm{cMLSS}=$ plasma lactate concentration at MLSS. TTE $=$ time to exhaustion at the MLSS. * Significant difference $(p<0.05)$ between males and females. 

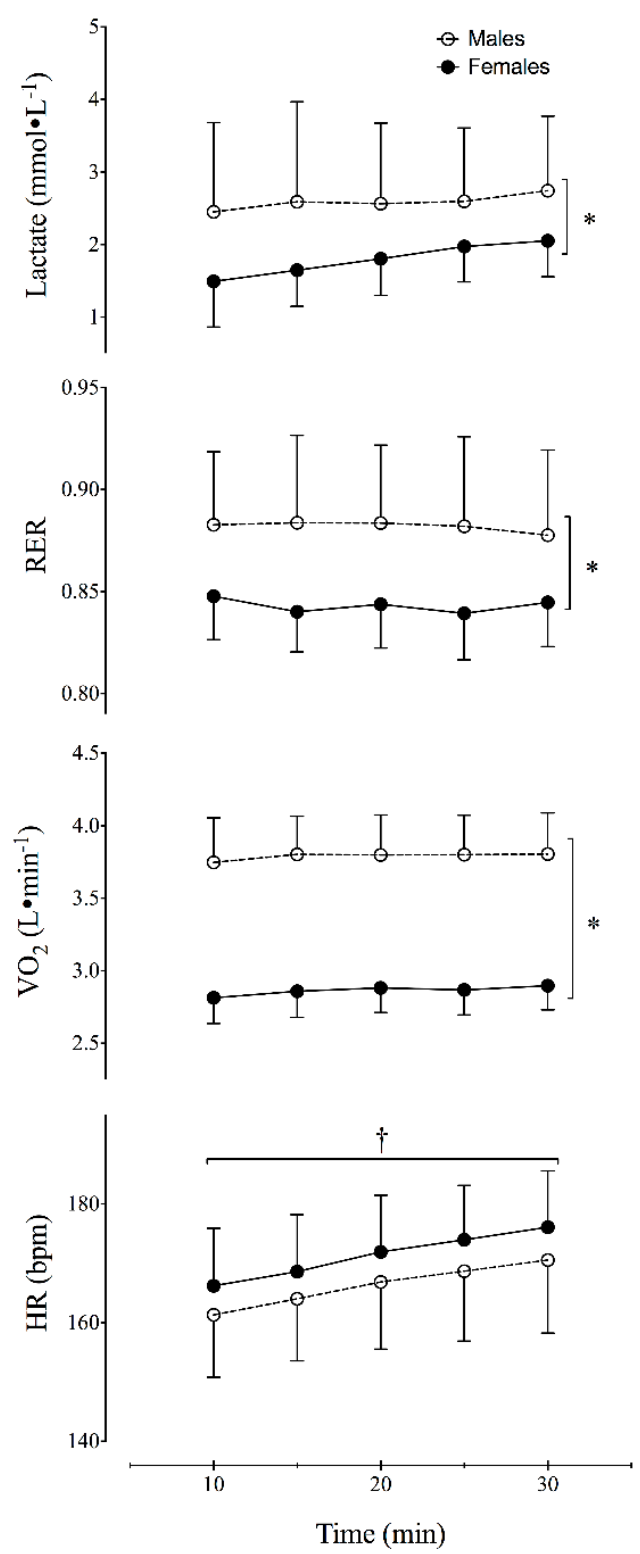

Figure 1. Time course of physiological variables during the MLSS running trial. Values reported are means \pm SD. ${ }^{*}$ Significant difference $(p<0.05)$ between males and females. ${ }^{\dagger}$ Significant change $(p<0.05)$ over time.

The MLSS occurred at similar relative intensities in males and females $(83 \pm 4.6$ and $83 \pm 6.7 \% \mathrm{VO}_{2}$ max, respectively). Additionally, both groups demonstrated steady-state $\mathrm{VO}_{2}$ kinetics during the MLSS trials (Figure 1 ) as the $\mathrm{VO}_{2}$ did not change significantly $(p=0.3739)$ between the 10th and 30th minutes of the vMLSS trial. The relative HR (\%HRmax) at the MLSS was also similar between males and females $(89.5 \pm 8.8$ and $88.6 \pm 6.8 \%$ HRmax, respectively). In both groups, HR increased significantly $(p=0.0007)$ over time during the vMLSS trial (Figure 1$)$. This rate of increase was approximately $0.48 \mathrm{bpm}$ (95\% CI: 0.21 to $0.76 \mathrm{bpm})$.

Of the subset of 8 participants who ran at a treadmill speed representing the vRER $=1.0,7$ achieved RER values between 0.97 and 0.99 and ran for 9.4-15.25 min. One participant achieved an RER $=1.05$ and was only able to run for $6 \mathrm{~min}$ before voluntarily terminating the test due to fatigue. Finally, there was not a significant difference $(p=0.4580)$ in TTE between the male $(79 \pm 17 \mathrm{~min})$ and female runners $(80 \pm 25 \mathrm{~min})$ at the vMLSS (Table 2). 


\section{Discussion}

Previous research suggested that the vMLSS may be similar to the speed at which RER $=1.0$ during a maximal GXT $[11,12,25,26]$. The results of this study (Table 2; Figure 1) indicate that the RER at the vMLSS is considerably less than 1.0 in well-trained runners. Additionally, the RER at the MLSS was significantly lower in female runners $(0.84 \pm 0.02)$ compared to male runners $(0.88 \pm 0.04)$. The results of this study suggest that the use of an RER value to estimate the vMLSS varies depending on the sex and training status of the athlete.

The lower RER values at the vMLSS in the female runners in this study are supported by the tendency of females to exhibit lower RER values and greater rates of fat oxidation at a given relative sub-maximal intensity of exercise [8]. Additional experimental research involving sex-hormone supplementation in men has recently begun to unravel the particular mechanisms of observed sex differences in substrate utilization during exercise. For example, when supplementing men with estrogen, lower RER values have been observed both at rest and during exercise [27]. Furthermore, this type of supplementation seems to be regulating the expression of genes involved in the oxidation of fat, such as peroxisome proliferator-activated receptor $\gamma$ coactivator- $1 \alpha$ (PGC- $1 \alpha)$ and microRNA-29b [28]. Therefore, it appears as though the lower RER, and increased fat oxidation, observed during submaximal exercise in females may be heavily influenced by sex hormones.

The lower RER observed at the vMLSS in the well-trained female runners in our study was also accompanied by a lower cMLSS (Table 2, Figure 1). The findings of this study are contrary to a recent report [19] that the RER and blood lactate concentrations did not differ between men and women while cycling at the MLSS intensity. The reported blood lactate levels for their male and female participants $\left(4.80 \pm 1.50 \mathrm{mmol} \cdot \mathrm{L}^{-1}\right.$ and $5.22 \pm 1.52 \mathrm{mmol} \cdot \mathrm{L}^{-1}$, respectively) are higher than the concentrations observed in this study (Table 2). Participants in the previous study [19] represented a heterogeneous group of males and females who reported a weekly combined training volume of 0-24.5 h/week in a variety of endurance activities (running, cycling, and swimming), resistance exercise, game sports (e.g., tennis, badminton, soccer, volleyball) and various other physical activities (e.g., dance, canoeing). Therefore, we believe that the heterogeneous nature of the participants training background prevented the researchers from identifying sex-related differences in the RER and cMLSS.

The mean blood lactate concentrations at the vMLSS for males have ranged between 3 and $6 \mathrm{mmol} \cdot \mathrm{L}^{-1}$ depending on the mode of exercise $[9,11,12,14,29,30]$. Although Beneke et al. [14] reported an average cMLSS of $4.9 \pm 1.5 \mathrm{mmol} \cdot \mathrm{L}^{-1}$ during cycling in 33 male participants, the cMLSS ranged from 1.9 to $7.5 \mathrm{mmol} \cdot \mathrm{L}^{-1}$. This wide range of cMLSS was likely due to the fact that 10 of the participants were trained cyclists while the remaining 23 participants were not trained. Our attempt to preserve homogeneity within groups likely decreased the variability of both the RER and cMLSS measures, minimizing the potential confounding effects of training status and endurance capacity.

Such discrepancies in the results of this study compared to previous studies may also be attributed to the methods used to measure blood lactate. In this study, plasma blood lactate was measured in triplicate from a blood sample drawn from an intravenous catheter. Other studies have measured blood lactate from a single 20-25 $\mu \mathrm{L}$ whole blood capillary blood sample taken from the ear lobe either during a 15-30 s rest period between each 5 min interval of exercise [9,12], or while the participant was exercising $[11,14,17,29]$. Such measurement techniques may contribute to differences between studies as we used centrifuged blood taken from the arm via an intravenous catheter and corrected for potential fluctuations in the hemodynamics associated with exercise [24].

Previous research tested the hypothesis that the intensity of exercise associated with an RER $=1.0$ was an accurate estimate of the intensity of exercise associated with the MLSS during leg ergometry [11] and running [12]. The cycling workload [11] and running speed [12] associated with an RER $=1.0$ during an incremental maximal exercise test of 1-min stages was used to estimate the intensity of exercise corresponding to the MLSS, despite, as the authors admit [11], insufficient time during each stage to assure steady-state gas exchange data. Laplaud et al. [11] reported that the RER remained near 1.0 during the MLSS exercise trial and that the MLSS workload corresponded to a similar workload 
during the maximal exercise test when $R E R=1.0$. For the participants in our study, running at an $\mathrm{RER}=1.0$ would represent an intensity of exercise at or above their $\mathrm{VO}_{2} \max$ in 9 of the 22 participants. Furthermore, subjects in this study were only able to run at the vRER $=1.0$ (RER $=0.97-1.05)$ for an average of $10.35 \mathrm{~min}$. Thus, our data are contrary to reports that intensities of exercise eliciting an $\mathrm{RER} \approx 1.0$ can be maintained for prolonged periods of time $[11,12,26,31]$. The RER values recorded in the male runners in this study at the vMLSS $($ RER $=0.88)$ are more in line with previously reported values (RER $\approx 0.93$ ) at the vMLSS in well-trained male runners [17] and cyclists [32].

It is important to note that much of the previous research [11,12,17] on RER at the MLSS did not describe any pre-exercise dietary controls aside from advising participants to maintain their regular diet the day prior to testing and to report to the lab at the same time of day for each test. As exercising in the fed state results in higher rates of carbohydrate oxidation, and therefore a higher RER during exercise [4], it is reasonable to suggest that the lower RER values observed at the MLSS in the runners in this study may be due to performing all exercise tests in a fasted state.

Although the exercise test to determine the cMLSS and vMLSS is $30 \mathrm{~min}$ in duration, it is presumed that the vMLSS can be maintained for extended durations [16] and is predictive of performance in all endurance-type sports [26]. Our results were not in support of our second hypothesis that a lower RER in females would be accompanied by superior endurance time at the vMLSS. The TTE at the vMLSS reported in this study (Table 2) ranged from $40 \mathrm{~min}$ to $97 \mathrm{~min}$ in males and from $40 \mathrm{~min}$ to $120 \mathrm{~min}$ in females. These times are considerably greater than the $35 \mathrm{~min}$ previously reported in moderately trained participants during cycling and running [33]. In support of our observations, more recent studies have reported a TTE at MLSS ranging from approximately $54 \mathrm{~min}$ [18] to $70 \mathrm{~min}$ [13] during cycling.

Complicating our current understanding of the particular mechanisms of fatigue at the MLSS is the concept that fatigue during prolonged exercise can be attributed to an interplay of various factors including: energy reserve status [34], hydration status [35], body temperature [36], the accumulation of lactate and $\mathrm{H}^{+}$[37], and central motor command [38]. Not surprisingly, research by Baron et al. [39] was unable to associate fatigue at the MLSS with evidence of failure in any single physiological system. Given the variability in the observed TTE in this study, and between other studies, we suspect the mechanism of fatigue to be different between individuals. Also, as our TTE is among the highest reported, we suspect that most individuals may experience long-term training adaptations to promote a higher TTE at the vMLSS.

Future research into individual mechanisms of fatigue at the MLSS may be beneficial to both coaches and athletes in order to effectively utilize and manipulate this intensity as part of a specific exercise regimen. Perhaps future research involving the measure of MLSS and TTE over longer periods of training may shed light on these discrepancies and aid in the understanding of the MLSS as an exercise intensity, as it relates to fatigue and performance.

\section{Conclusions}

Our findings suggest that the metabolic intensity of MLSS is sex-specific, with female runners exhibiting lower RER values, higher fat oxidation rates, and lower plasma lactate concentrations, despite working at a similar relative intensity of exercise $\left(\% \mathrm{VO}_{2} \max \right)$ as their male counterparts. We suggest that estimates of the vMLSS from gas exchange variables should also be sex-specific. However, these differences do not seem to influence the interpretation of the MLSS as a general training intensity in well-trained runners as $\% \mathrm{VO}_{2} \max , \% \mathrm{HRmax}$, and TTE at vMLSS were identical between male and female runners. Thus, the application of MLSS as a training tool may revolve around similar relative intensities and durations independent of sex.

Author Contributions: Conceptualization, P.S.H. and P.R.V.; Methodology, P.S.H. and P.R.V.; Validation, P.S.H. and P.R.V.; Formal Analysis, P.S.H.; Investigation, P.S.H. and P.R.V.; Data Curation, P.S.H. and P.R.V.; Writing-Original Draft Preparation, P.S.H.; Writing-Review \& Editing, P.S.H. and P.R.V.; Supervision, P.S.H. and P.R.V.; Project Administration, P.R.V. 
Funding: This research received no external funding.

Acknowledgments: The authors would like to acknowledge the contributions of the following students in the collection of data in this research project: Sean Catlett, Hailey Darger, Amanda Gier, Mark MacKay, Adriana Mooth, Andy Larsen, Kurtis Rosengreen, Gregory Savio, and Parker Wood.

Conflicts of Interest: The authors declare no conflicts of interest.

\section{References}

1. Coyle, E.F.; Holloszy, J.O. Integration of the physiological factors determining endurance performance ability. In Exercise and Sport Sciences Reviews; Holloszy, J.O., Ed.; Williams \& Wilkins: Baltimore, MD, USA, 1995; pp. 25-63.

2. Bassett, D.R.; Howley, E.T. Limiting factor for maximum oxygen uptake and determinants of endurance performance. Med. Sci. Sports Exerc. 2000, 32, 70-84. [CrossRef] [PubMed]

3. Plowman, S.A.; Smith, D.L. Exercise Physiology for Health, Fitness, and Performance, 4th ed.; Lippincott Williams \& Wilkins: Baltimore, MD, USA, 2014; pp. 102-110.

4. Bergman, B.C.; Brooks, G.A. Respiratory gas-exchange ratios during graded exercise in fed and fasted trained and untrained men. J. Appl. Physiol. 1999, 86, 479-487. [CrossRef] [PubMed]

5. Gaesser, G.A.; Brooks, G.A. Muscular efficiency during steady-rate exercise: Effects of speed and work rate. J. Appl. Physiol. 1975, 38, 1132-1139. [CrossRef] [PubMed]

6. Goedecke, J.H.; Gibson, A.S.; Grobler, L.; Collins, M.; Noakes, T.D.; Lambert, E.V. Determinants of the variability in respiratory exchange ratio at rest and during exercise in trained athletes. Am. J. Physiol. Endocrinol. Metab. 2000, 279, E1325-E1334. [CrossRef] [PubMed]

7. Horton, T.J.; Pagliassotti, M.J.; Hobbs, K.; Hill, J.O. Fuel metabolism in men and women during and after long-duration exercise. J. Appl. Physiol. 1998, 85, 1823-1832. [CrossRef] [PubMed]

8. Tarnopolsky, L.J.; MacDougall, J.D.; Atkinson, S.A.; Tarnopolsky, M.A.; Sutton, J.R. Gender differences in substrate for endurance exercise. J. Appl. Physiol. 1990, 68, 302-308. [CrossRef] [PubMed]

9. Beneke, R. Anaerobic threshold, individual anaerobic threshold, and maximal lactate steady state in rowing. Med. Sci. Sports Exerc. 1995, 27, 863-867. [CrossRef] [PubMed]

10. Lajoie, C.; Laurencelle, L.; Trudeau, F. Physiological responses to cycling for 60 min at maximal lactate steady state. Can. J. Appl. Physiol. 2000, 25, 250-261. [CrossRef] [PubMed]

11. Laplaud, D.; Guinot, M.; Favre-Juvin, A.; Flore, P. Maximal lactate steady state determination with a single incremental test exercise. Eur. J. Appl. Physiol. 2006, 96, 446-452. [CrossRef] [PubMed]

12. Leti, T.; Mendelson, M.; Laplaud, D.; Flore, P. Prediction of maximal lactate steady state in runners with an incremental test on the field. J. Sports Sci. 2012, 30, 609-616. [CrossRef] [PubMed]

13. Mendes, T.T.; Fonseca, T.R.; Ramos, G.P.; Wilke, C.F.; Cabido, C.E.; De Barros, C.L.; Lima, A.M.; Mortimer, L.D.; de Carvalho, M.V.; Teixeira, M.M.; et al. Six weeks of aerobic training improves VO2max and MLSS but does not improve the time to fatigue at the MLSS. Eur. J. Appl. Physiol. 2013, 113, 965-973. [CrossRef] [PubMed]

14. Beneke, R.; Hutler, M.; Leithauser, R.M. Maximal lactate-steady-state independent of performance. Med. Sci. Sports Exerc. 2000, 32, 1135-1139. [CrossRef] [PubMed]

15. Haverty, M.; Kenney, W.L.; Hodgson, J.L. Lactate and gas exchange responses to incremental and steady state running. Br. J. Sports Med. 1988, 22, 51-54. [CrossRef] [PubMed]

16. Billat, V.L.; Demarle, A.; Slawinksi, J.; Koralsztein, J.P. Physical and training characteristics of top-class marathon runners. Med. Sci. Sports Exerc. 2001, 33, 2089-2097. [CrossRef] [PubMed]

17. Dittrich, N.; de Lucas, R.D.; Beneke, R.; Guglielmo, L.G.A. Time to exhaustion at continuous and intermittent maximal lactate steady state during running exercise. Int. J. Sports Phys. Per. 2014, 9, 772-776. [CrossRef] [PubMed]

18. Gross, T.; De Lucas, R.D.; De Souza, K.M.; Guglielmo, L.G. Time to exhaustion at intermittent maximal lactate steady state is longer than continuous cycling exercise. Appl. Physiol. Nutr. Metab. 2012, 37, 1047-1053. [CrossRef] [PubMed] 
19. Smekal, G.; von Duvillard, S.P.; Pokan, R.; Hofmann, P.; Braun, W.A.; Arciero, P.J.; Tschan, H.; Wonisch, M.; Baron, R.; Bachl, N. Blood lactate concentration at the maximal lactate steady state is not dependent on endurance capacity in healthy recreationally trained individuals. Eur. J. Appl. Physiol. 2012, 112, 3079-3086. [CrossRef] [PubMed]

20. Hackney, A.C.; McCracken-Compton, M.A.; Ainsworth, B. Substrate responses to submaximal exercise in the midfollicular and midluteal phases of the menstrual cycle. Int. J. Sport Nutr. 1994, 4, 299-308. [CrossRef] [PubMed]

21. Jurkowski, J.E.H.; Jones, N.L.; Toews, C.J.; Sutton, J.R. Effects of menstrual cycle on blood lactate, 02 delivery, and performance during exercise. J. Appl. Physiol. 1981, 51, 1493-1499. [CrossRef] [PubMed]

22. Zderic, T.W.; Coggan, A.R.; Ruby, B.C. Glucose kinetics and substrate oxidation during exercise in the follicular and luteal phases. J. Appl. Physiol. 2001, 90, 447-453. [CrossRef] [PubMed]

23. Noble, B.J.; Borg, G.A.V.; Jacobs, I.; Ceci, R.; Kaiser, P. A category-ratio perceived exertion scale: Relationship to blood and muscle lactates and heart rate. Med. Sci. Sports Exerc. 1983, 15, 523-528. [CrossRef] [PubMed]

24. Dill, D.B.; Costill, D.L. Calculation of percentage changes in volumes of blood, plasma, and red cells in dehydration. J. Appl. Physiol. 1974, 37, 247-248. [CrossRef] [PubMed]

25. Billat, V.L. Use of blood lactate measurements for prediction of exercise performance and for control of training. Sports Med. 1996, 22, 157-175. [CrossRef] [PubMed]

26. Billat, V.L.; Sirvent, P.; Py, G.; Koralsztein, J.P.; Mercier, J. The concept of maximal lactate steady state. Sports Med. 2012, 33, 407-426. [CrossRef] [PubMed]

27. Hamadeh, M.J.; Devries, M.C.; Tarnopolsky, M.A. Estrogen supplementation reduces whole body leucine and carbohydrate oxidation and increases lipid oxidation in men during endurance exercise. J. Clin. Endocrinol. Metab. 2005, 90, 3592-3599. [CrossRef] [PubMed]

28. Maher, A.C.; Akhtar, M.; Tarnopolsky, M.A. Men supplemented with 17beta-estradiol have increased beta-oxidation capacity in skeletal muscle. Phsyiol. Genom. 2010, 42, 342-347. [CrossRef] [PubMed]

29. Beneke, R.; von Duvillard, S.P. Determination of maximal lactate steady state response in selected sports events. Med. Sci. Sports Exerc. 1996, 28, 241-246. [CrossRef] [PubMed]

30. Billat, V.L.; Sirvent, P.; Lepretre, P.M.; Koralsztein, J.P. Training effect of performance, substrate balance and blood lactate concentration at maximal lactate steady state in master endurance-runners. Pflugers Arch. 2004, 447, 875-883. [CrossRef] [PubMed]

31. O’Brien, M.J.; Viguie, C.A.; Mazzeo, R.S.; Brooks, G.A. Carbohydrate dependence during marathon running. Med. Sci. Sports Exerc. 1993, 25, 1009-1017. [PubMed]

32. Helge, J.W.; Watt, P.W.; Richter, E.A.; Rennie, M.J.; Kiens, B. Fat utilization during exercise: Adaptation to a fat-rich diet increases utilization of plasma fatty acids and very low density lipoprotein-triacylglycerol in humans. J. Phys. 2001, 537, 1009-1020. [CrossRef]

33. Fontana, P.; Boutellier, U.; Knopfli-Lenzin, C. Time to exhaustion at maximal lactate steady state is similar for cycling and running in moderately trained subjects. Eur. J. Appl. Physiol. 2009, 107, 187-192. [CrossRef] [PubMed]

34. Bergstrom, J.; Hermansen, L.; Hultman, E.; Saltin, B. Diet, Muscle glycogen and physical performance. Acta Physiol. Scand. 1967, 71, 140-150. [CrossRef] [PubMed]

35. Coyle, E.F. Fluid and Fuel Intake During Exercise. J. Sports Sci. 2004, 22, 39-55. [CrossRef] [PubMed]

36. Gonzalez-Alonso, J.; Teller, C.; Andersen, S.L.; Jensen, F.B.; Hyldig, T.; Nielsen, B. Influence of body temperature on the development of fatigue during prolonged exercise in the heat. J. Appl. Physiol. 1999, 86, 1032-1039. [CrossRef] [PubMed]

37. Tesch, P.; Sjodin, B.; Thorstensson, A.; Karlsson, J. Muscle fatigue and its relation to lactate accumulation and LDH activity in man. Acta Physiol. Scand. 1978, 103, 413-420. [CrossRef] [PubMed]

38. Enoka, R.M. Mechanisms of muscle fatigue: Central factors and task dependency. J. Electromyogr. Kinesiol. 1995, 5, 141-149. [CrossRef]

39. Baron, B.; Noakes, T.D.; Dekerle, J.; Moullan, F.; Robin, S.; Matran, R.; Pelayo, P. Why does exercise terminate at the maximal lactate steady state intensity? Br. J. Sports Med. 2008, 42, 828-833. [CrossRef] [PubMed]

(C) 2018 by the authors. Licensee MDPI, Basel, Switzerland. This article is an open access article distributed under the terms and conditions of the Creative Commons Attribution (CC BY) license (http://creativecommons.org/licenses/by/4.0/). 